\title{
Effects of high-dose B vitamin complex with vitamin $C$ and minerals on subjective mood and performance in healthy males
}

\author{
David O. Kennedy • Rachel Veasey • Anthony Watson • \\ Fiona Dodd • Emma Jones • Silvia Maggini • \\ Crystal F. Haskell
}

Received: 20 November 2009 / Accepted: 16 April 2010/Published online: 8 May 2010

(C) The Author(s) 2010. This article is published with open access at Springerlink.com

\begin{abstract}
Rationale A significant proportion of the general population report supplementing their diet with one or more vitamins or minerals, with common reasons for doing so being to combat stress and fatigue and to improve mental functioning. Few studies have assessed the relationship between supplementation with vitamins/minerals and psychological functioning in healthy cohorts of non-elderly adults.

Objectives The present randomised, placebo-controlled, double-blind, parallel groups trial assessed the cognitive and mood effects of a high-dose B-complex vitamin and mineral supplement $\left(\right.$ Berocca $\left.^{\circledR}\right)$ in 215 males aged 30 to 55 years, who were in full-time employment.

Methods Participants attended the laboratory prior to and on the last day of a 33-day treatment period where they completed the Profile of Mood States (POMS), Perceived Stress Scale (PSS) and General Health Questionnaire (GHQ-12). Cognitive performance and task-related modulation of mood/fatigue were assessed with the $60 \mathrm{~min}$ cognitive demand battery. On the final day, participants also completed the Stroop task for $40 \mathrm{~min}$ whilst engaged in inclined treadmill walking and subsequent executive function was assessed.
\end{abstract}

D. O. Kennedy $\cdot$ R. Veasey $\cdot$ A. Watson $\cdot$ F. Dodd $\cdot$ E. Jones $\cdot$

C. F. Haskell $(\square)$

Brain, Performance and Nutrition Research Centre,

Northumbria University,

Newcastle-upon-Tyne NE1 8ST, UK

e-mail: crystal.haskell@northumbria.ac.uk

S. Maggini

Bayer Consumer Care Ltd,

Basel, Switzerland
Results Vitamin/mineral supplementation led to significant improvements in ratings on the PSS, GHQ-12 and the 'vigour' subscale of the POMS. The vitamin/mineral group also performed better on the Serial 3s subtractions task and rated themselves as less 'mentally tired' both pre- and postcompletion of the cognitive demand battery.

Conclusions Healthy members of the general population may benefit from augmented levels of vitamins/minerals via direct dietary supplementation. Specifically, supplementation led to improved ratings of stress, mental health and vigour and improved cognitive performance during intense mental processing.

Keywords Vitamin · Mineral Cognition · Cognitive . Executive function · Mood - Supplementation - Deficiency Stress

\section{Introduction}

Optimum functioning of the central nervous system is dependent on a wide range of micronutrients. For example, folic acid and vitamins B12 and B6 play specific roles in the methylation and decarboxylation processes that govern the integrity of DNA, and the synthesis of DNA, proteins, phospholipids and monoamine and catecholamine neurotransmitters (Mattson and Shea 2003). All three vitamins also play key roles in the remethylation and metabolism of the potentially toxic amino acid homocysteine, increased levels of which may contribute to a range of neurodegenerative and psychiatric disorders via a host of deleterious effects to cellular, haemodynamic, oxidative and vascular parameters (Mattson and Shea 2003). Vitamin C is also the brain's most prevalent antioxidant and is found at its 
greatest concentrations in neuron rich areas. Evidence suggests that its one-electron donor properties make it an essential co-factor in a plethora of processes that underlie neural maturation, neuroprotection and neurotransmission (Harrison and May 2009). Similarly, a number of minerals, including zinc, magnesium and calcium, are essential for adequate functioning of the central nervous system, and play diverse roles including in myelination, neurotransmitter synthesis and modulation of activity in the dopaminergic and adenosinergic neurotransmitter systems (Black 1996; Cardoso et al. 2009; Gareri et al. 1995).

There is a wealth of evidence from epidemiological studies that clearly suggest a relationship between micronutrients and psychological functioning. The largest body of work, mainly conducted in older cohorts, has demonstrated that circulating levels of one or more B vitamins and/or homocysteine are related to depression (Bjelland et al. 2003; Kim et al. 2008; Sanchez-Villegas et al. 2009; Tiemeier et al. 2002), and cognitive performance (Durga et al. 2006; Duthie et al. 2002; Elias et al. 2006, 2008; Feng et al. 2006; Kado et al. 2005; Vidal et al. 2008). However, the inter-relationship between $\mathrm{B}$ vitamins and homocysteine levels and the causality of the relationships with brain function have not yet been adequately elucidated (Elias et al. 2006). A number of epidemiological studies conducted in older participants have also demonstrated a relationship between cognitive performance, or risk of dementia, and vitamin C intake (Del Parigi et al. 2006; Engelhart et al. 2002).

The case for direct intervention with supplements as assessed by controlled trials is less clear. Three recently updated Cochrane reviews examined the efficacy of vitamin B6 (Malouf and Grimley Evans 2003); B12 (Malouf and Sastre 2003) and B9 with or without B12 (Malouf and Grimley Evans 2008) in attenuating the cognitive declines associates with age and dementia. These reviews all concluded that there is no consistent evidence for efficacy on the basis of the small number of studies that met their inclusion criteria. The authors recommend that further work is needed in this area. A trial conducted by Durga et al. (2007), cited in the latter review as being methodologically adequate, showed that 3 years supplementation with folic acid in 81850 - to 70-year-old participants, selected on the basis of high homocysteine levels, led to decreased homocysteine and improved memory function, information processing and sensorimotor speed. The authors also note a number of methodological concerns across the studies in this area, including the use of insensitive instruments such as the Mini-Mental State Exam, which may account for the lack of consistent evidence in this area. As with B vitamins, the evidence for direct supplementation with vitamin $\mathrm{C}$ in elderly or dementia suffering cohorts is also somewhat equivocal (Morris 2009).
In terms of supplementation with a fuller range of vitamins and minerals, a number of studies have been conducted in cohorts of children. Benton (2001), reviewing the results of the effects of multi-vitamins/minerals on children's intelligence (IQ) across 13 studies, noted some evidence of improved performance that was restricted to non-verbal tests of intelligence. Following a subsequent meta-analysis, Eilander et al. (2010) concluded, on the basis of a non-significant trend, that there was a 'possibility of a small positive effect' of supplementation on similar measures of fluid intelligence and evidence of a significant improvement in academic achievement from a small sub-set of studies. A further randomised, placebo-controlled study has also been completed after the inclusion period for these reviews. Haskell et al. (2008) demonstrated benefits to cognitive performance in children during 12 weeks supplementation with a multi-vitamins/mineral. With regards adults, Benton et al. (1995a, b) showed that 12 months supplementation with a high-dose multi-vitamin was able to improve subjective mood (Profile of Mood StatesPOMS), mental health (General Health QuestionnaireGHQ) and cognitive performance on attention tasks. However, these effects were restricted to the females within the sample (Benton et al. 1995a, b). Schlebusch et al. (2000), in a placebo-controlled trial involving 300 healthy adults, found that 4 weeks administration of a vitamin $\mathrm{B}$ complex with vitamin $\mathrm{C}$ and minerals (Berocca Calmag ${ }^{\circledR}$ ) improved subjective ratings of stress, anxiety and psychological well-being. Similarly, Carroll et al. (2000), assessing the effects of a similar supplement (Berocca $\left.{ }^{\circledR}\right)$ in a sample of 80 healthy males, also reported significantly attenuated subjective stress (Perceived Stress Scale-PSS) and anxiety (Hospital Anxiety and Depression Scale) in healthy males following 4 weeks supplementation.

The current randomised, double-blind, placebocontrolled, parallel groups trial therefore assessed the effects of 33-days supplementation with a high-dose B vitamin complex plus vitamin $\mathrm{C}$ and minerals $\left(\right.$ Berocca $\left.^{\circledR}\right)$ on cognitive performance, mood and well-being in healthy males in full-time employment. High levels of cognitive demand, and the resultant mental fatigue during testing, may provide a sensitive backdrop for the measurement of treatment-related cognitive enhancement. Laboratoryinduced mental fatigue has also been shown to disrupt tasks that require high levels of executive control of cognitive processes (Kato et al. 2009; Lorist et al. 2009), and these fatigue-related decrements may also afford a more sensitive backdrop for assessing enhancement. This exploratory study therefore employed a cognitive demand battery $(\mathrm{CDB})$ that elicits mental fatigue and which has been shown to be sensitive to a number of natural interventions (Kennedy et al. 2008; Reay et al. 2005) and included the performance of executive function tasks during 
a state of fatigue inculcated by extended cognitive task performance and physical activity.

\section{Materials and methods}

\section{Participants}

Participants were recruited via email distribution, local press adverts, publicity on local radio and posters in the Newcastle upon Tyne area. Following screening and informed consent $(N=244)$ a total of 215 healthy males aged 30-55 years were randomised and completed this exploratory trial. During the blind data review process, further five participants were removed for major protocol violations (one non-compliance to treatment, one significant medical condition, three body mass index $(\mathrm{BMI})>40$ ), giving a per protocol sample of 210 evaluable participants (multi-vitamin/mineral, $N=103$; placebo, $N=107$ ). Demographic data for each group are given in Table 1.

Screening comprised training and familiarisation with tasks as well as ensuring participants met the inclusion criteria of being male, aged 30-55 years and in full-time employment and did not breech any exclusion criteria. These included having a clinically significant medical condition within the last 5 years, use of medication within the previous 5 days, use of any over-the-counter vitamins and/or other dietary supplements within the previous 4 weeks or any relevant food intolerances/sensitivity. Information relating to demographics and baseline characteristics of the two groups was also obtained at this point. This included age, BMI and average consumption of alcohol, cigarettes and fruit and vegetables. Consumption levels were measured simply by self-report following advice regarding what, according to government guidelines, constituted a portion in the case of fruit and vegetables and a unit in the case of alcohol.

Treatments

Participants received either placebo or a multi-vitamin/ mineral supplement $\left(\right.$ Berocca ${ }^{\circledR}$ ) in identical effervescent tablets. Participants ingested one tablet per day with water for the $33( \pm 2)$ days of the study. The multi-vitamin/mineral tablets contained vitamins: B1 $(15 \mathrm{mg}), \mathrm{B} 2(15 \mathrm{mg}), \mathrm{B} 6$ $(10 \mathrm{mg}), \mathrm{B} 12(10 \mathrm{mcg}), \mathrm{C}(500 \mathrm{mg})$, biotin $(150 \mathrm{mcg})$, folic acid $(400 \mathrm{mcg})$, nicotinamide $(50 \mathrm{mg})$ and pantothenic acid $(23 \mathrm{mg})$ and minerals: calcium $(100 \mathrm{mg})$, magnesium $(100 \mathrm{mg})$ and zinc $(10 \mathrm{mg})$. Participants were assigned to treatment groups in accordance with a computer-generated randomisation schedule provided by the manufacturer and were dispensed the study product designated to the corresponding randomisation number. Participants returned all unused treatment at the final visit. Compliance (between $80 \%$ and $120 \%$ of the treatment) was assessed via tablet counting and treatment diary cards.

Cognitive and mood measures

With the exception of the paper and pencil questionnaires all tasks and visual analogue scales were administered using the Computerised Mental Performance Assessment System (COMPASS - Kennedy and Haskell under review), a platform for the presentation of computerised tasks derived from standard psychometric measures.

\section{Fatigue and mood}

GQH-12 (Goldberg et al. 1997) The General Health Questionnaire is a screening instrument used for assessing
Table 1 Demographics for the placebo and multi-vitamin/ mineral groups

\begin{tabular}{|c|c|c|c|c|}
\hline & \multicolumn{2}{|c|}{ Placebo $(N=107)$} & \multicolumn{2}{|c|}{ Multi-vitamin/mineral $(N=103)$} \\
\hline & Mean & SD & Mean & SD \\
\hline Age & 38.8 & 6.35 & 39.7 & 7.08 \\
\hline Height & 1.79 & 0.07 & 1.80 & 0.64 \\
\hline Weight & 85.6 & 12.5 & 86.6 & 12.0 \\
\hline BMI & 26.6 & 3.37 & 26.8 & 3.38 \\
\hline Systolic blood pressure & 136 & 13.5 & 136 & 13.7 \\
\hline Diastolic blood pressure & 88.0 & 9.66 & 87.6 & 9.51 \\
\hline Heart rate & 71.0 & 11.4 & 70.1 & 12.1 \\
\hline Respiratory rate & 16.6 & 4.89 & 16.8 & 6.29 \\
\hline Temperature & 35.9 & 1.00 & 35.9 & 0.87 \\
\hline Fruit and vegetables (portions per day) & 3.20 & 1.48 & 3.71 & 2.00 \\
\hline Alcohol (units per week) & 15.0 & 10.9 & 13.3 & 11.0 \\
\hline Cigarettes (no. per day) & 1.41 & 4.77 & 0.88 & 2.75 \\
\hline
\end{tabular}


general psychological health both in clinical settings and in non-clinical research settings requiring repeated measurements over time. The GHQ-12 consists of 12 items, each assessing the severity of a mental problem over the past few weeks using a 4-point scale (from 0 to 3 ) with higher scores indicating worse conditions (Goldberg and Williams 1988).

PSS (Cohen et al. 1983) The PSS is a 10-item questionnaire that assesses the degree to which situations in one's life are appraised as stressful using a 5-point scale (0-4). It is a widely used research instrument and its validity has been established within a number of populations (Froelicher et al. 2004; Golden-Kreutz et al. 2004; Mimura and Griffiths 2004).

POMS (McNair et al. 1992) The POMS is a wellestablished, factor-analytically derived measure of psychological distress for which high levels of reliability and validity have been documented. The POMS consists of 65 adjectives rated on a $0-4$ scale that can be consolidated into 'depression-dejection', 'tension-anxiety', 'anger-hostility', 'confusion-bewilderment', 'vigour-activity' and 'fatigueinertia' sub-scales. The latter two sub-scales can be interpreted as measures of fatigue and have been validated as separate factors in a number of studies. Norms have been published for a variety of patient and non-patient groups.

Bond-Lader mood scales (Bond and Lader 1974) The Bond and Lader scales have been utilised in numerous pharmacological, psychopharmacological and medical trials. These scales comprise a total of $16100 \mathrm{~mm}$ lines anchored at either end by antonyms (e.g., 'alert-drowsy', 'calm-excited'). Participants indicate their current subjective position between the antonyms on the line. Outcomes comprise three factor analysis derived scores: 'Alertness', 'Calmness' and 'Contentment'.

Energy visual analogue scales Visual analogue scales (VAS) anchored at either end by 'very low' and 'very high' assessed the participants' self-rated levels of 'concentration', 'mental stamina' and 'physical stamina'. VAS anchored at either end by 'not at all' and 'extremely' assessed the participants' self-rated fatigue levels of being 'mentally tired' and 'physically tired'.

\section{Cognitive tasks}

$C D B$ This battery is designed to assess the impact of treatment on speed/accuracy and mental fatigue during continuous performance of cognitively demanding tasks. The working hypothesis underlying this approach is that any psychoactive properties of a test substance are liable to be more readily apparent during a period of intense cognitive demand and the 'mental fatigue' state elicited by this prolonged task performance.

In the current study, the battery performed a second role as part of the mental component in the inculcation of mental and physical fatigue in participants. Application of this battery in its usual $60 \mathrm{~min}$ form has been shown to reliably increase self-ratings of 'mental fatigue' and to be sensitive to a number of natural interventions (Kennedy et al. 2008; Kennedy and Scholey 2004; Reay et al. 2005). The effects of this battery tend to increase towards the later stages of completion. The 10-min battery (which is repeated six times) comprises:

\section{Serial subtractions ( $3 s$ and $7 s-2$ min each)}

The original verbal Serial $7 \mathrm{~s}$ test has appeared in a number of forms, including as part of the Mini-Mental State Examination for dementia screening. In the current study modified, 2-min computerised versions of the Serial 3s and Serial $7 \mathrm{~s}$ tests were utilised (Scholey et al. 2010). At the start of each 2-min section, a standard instruction screen informed the participant to count backwards in threes or sevens, as quickly and accurately as possible, using the linear number keys of the keyboard to type in each response. Participants were also instructed verbally at the outset that if they were to make a mistake they should carry on subtracting from the new incorrect number. A random starting number between 800 and 999 was presented on the computer screen, which was cleared by the entry of the first response. Each three-digit response was represented on screen by an asterisk. Pressing the enter key signalled the end of each response and cleared the three asterisks from the screen. Performance data (number of correct subtractions and number of errors performed during the $2 \mathrm{~min}$ task) were calculated for the Serial $3 \mathrm{~s}$ and $7 \mathrm{~s}$ elements, separately. In the case of incorrect responses, subsequent responses were scored as positive if they were correct in relation to the new number.

\section{Rapid visual information processing task (5 min)}

In this task, the participant monitored a continuous series of digits for targets of three consecutive odd or three consecutive even digits. The digits were presented at the rate of $100 \mathrm{~min}^{-1}$ and the participant responded to the detection of a target string by pressing a response key as quickly as possible. The task was continuous and lasted for $5 \mathrm{~min}$, with eight correct target strings being presented in each minute. The task was scored for percentage of target strings correctly detected, average reaction time for correct detections and number of false alarms.

\section{Subjective 'mental fatigue' scale}

Following each repetition of the battery of tasks, participants rated their subjective feeling of 'mental fatigue' via an on-screen $100-\mathrm{mm}$ visual analogue scale with the 
end-points labelled 'not at all' and 'extremely'. The scales were scored as percent along the line towards 'extremely'.

\section{Stroop task}

Whilst performing $40 \mathrm{~min}$ of inclined treadmill walking (Reebok 3-series treadmill), titrated to keep the participants heart rate at approximately $60 \%$ of the maximum heart rate for their age, participants performed the Stroop task. This task was used to both inculcate further mental fatigue and measure cognitive performance. This was a computerised version of a commonly used classic task (Stroop 1935), which requires attentional and central executive resources. In this case the task ran for $40 \mathrm{~min}$, with the data collapsed into four 10-min epochs. Words describing one of four colours ('RED', 'YELLOW', 'GREEN', 'BLUE') were presented in different coloured fonts in the centre of a computer screen stationed at eye level in front of the treadmill. The participant pressed one of four coloured response buttons mounted on the treadmill in order to identify the font colour (e.g., if the word 'GREEN' was presented in a blue font, the correct response would be to respond with the blue button). The presented words were either 'congruent' (word and font are the same colour) or 'incongruent' (word and font are different colours) and were presented in a random order. The task was scored for reaction times and accuracy of responses to 'congruent' and 'incongruent' words.

\section{Executive functioning tasks}

The following classic 'executive' tasks, which have been shown to be sensitive to fatigue (van der Linden et al. 2003), were utilised.

\section{Peg-and-ball task}

In this computerised version of the original 'Tower of London', executive function task participants were presented with two configurations of three coloured balls (blue, green, red) on three pegs that held three, two and one ball, respectively. The participants had to rearrange the balls from the starting configuration so that they matched the position of the balls in the goal configuration, moving one ball that did not have a ball above it at a time. Participants were asked to work out the entire planning sequence and calculate the minimum number of moves required prior to moving the balls using the mouse/cursor. Participants completed a total of 18 trials, comprising six trials each that could be solved in three, four and five moves, respectively, in ascending order of difficulty. Each trial generated scores for planning times prior to moving, time to complete and number of moves made above the minimum required to complete the task.

\section{Wisconsin card sort task (Berg 1948)}

This is a standard clinical measure that is commonly used as a measure of executive functioning and is thought to require cognitive flexibility, problem solving and the use of feedback to guide behaviour. In this computerised version of the test, participants were asked to match cards that varied by colour, shape and number to four 'key cards'. Participants were not told how to sort the cards, but were required to determine the correct category from the feedback given to their responses, which changed periodically throughout the test. In total the current version comprised the presentation of up to 128 cards. Overall accuracy, percentage of perseverative and non-perseverative errors committed and time to complete during the test were used as the measure of executive functioning.

\section{Procedure}

Within 14 days of the initial screening visit, participants arrived at the laboratory at $08.30 \mathrm{am}( \pm 30 \mathrm{~min})$ for their pre-treatment assessment (day -2 ). They completed an assessment of mood and well-being comprising the GHQ12 , the PSS, the POMS and Bond-Lader mood scales. Immediately after this they completed the $\mathrm{CDB}$ for $60 \mathrm{~min}$. Fatigue was assessed immediately before and after completion of the CDB with the 'Energy VAS'.

Participants were then dispensed their treatment for the 33 ( \pm 2 )-day treatment period and instructed to take one tablet dissolved in a full glass of water $(8 \mathrm{oz}$ or $250 \mathrm{ml}$ of water) every morning after waking beginning 2 days following the laboratory visit and thereafter throughout the study treatment period. They were also given a diary card to record intake of tablets and any general health observations.

Participants returned after 33 days of treatment (day $33 \pm$ 2 days where necessary) and completed exactly the same assessments. In addition to those tasks completed at baseline (pre-treatment assessment), they also completed the Stroop task for 40 min whilst engaged in inclined treadmill walking. They then completed the 'Energy VAS' for a final time before executive function was assessed with peg-and-ball and Wisconsin card sort tasks. The timelines of the two laboratory visits are shown in Fig. 1. Details of the tasks and timelines for the final laboratory visit (day $33 \pm 2$ ) are shown in Fig. 2.

\section{Statistics}

Prior to analysis of the day 33 data, any baseline differences on the performance and questionnaire measures and any underlying cohort differences in terms of demographic and lifestyle variables were assessed with one-way (treatment) ANOVA. 
Fig. 1 Timelines for the pre-treatment (day -2$)$ and posttreatment (day $33 \pm 2$ ) visits to the laboratory

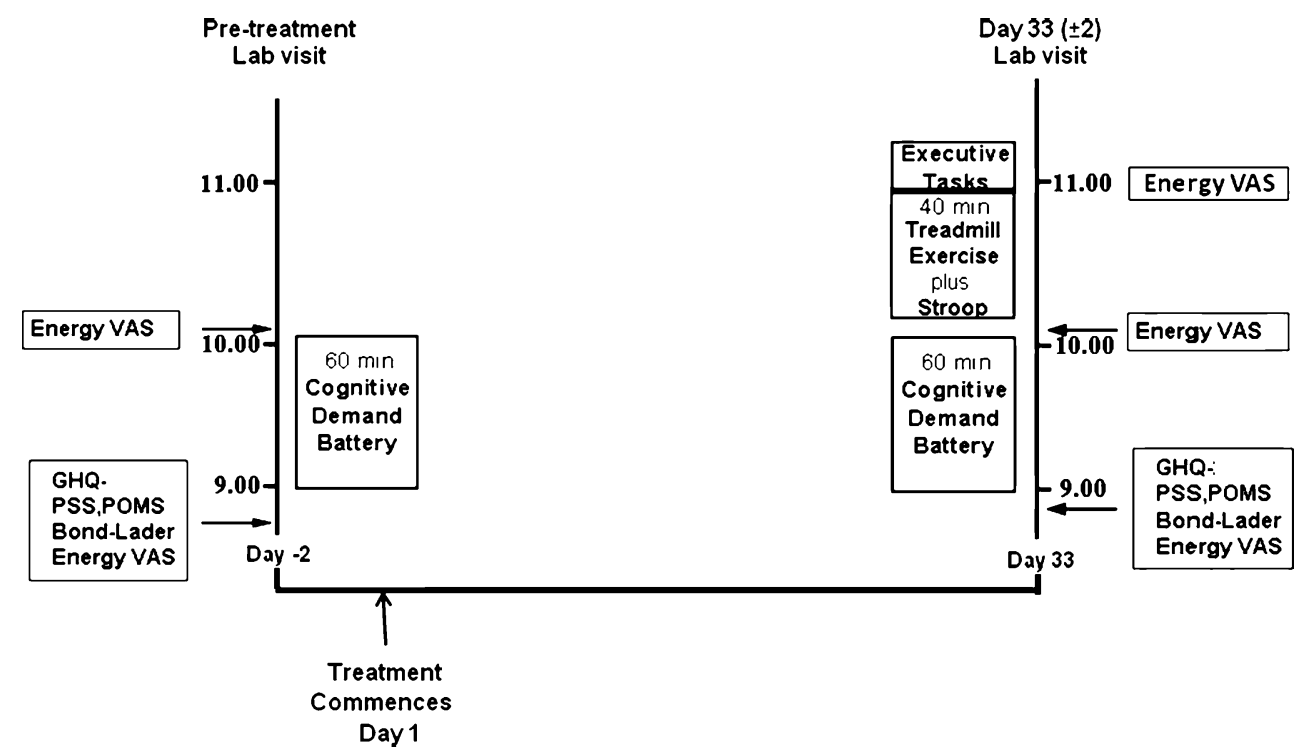

\section{Questionnaires}

All total and subscale scores for the GHQ-12, PSS, POMS and Bond-Lader questionnaires on day 33 were analysed with one-way (treatment) ANCOVA using the respective pre-treatment score as a covariate.

\section{$C D B$ scores, mental fatigue and subjective fatigue/energy} during completion

Scores for the six repetitions of the CDB and ratings on the 'Mental Fatigue' and the two repetitions of the 'Energy VAS' (completed before and after the CDB) on day 33 were

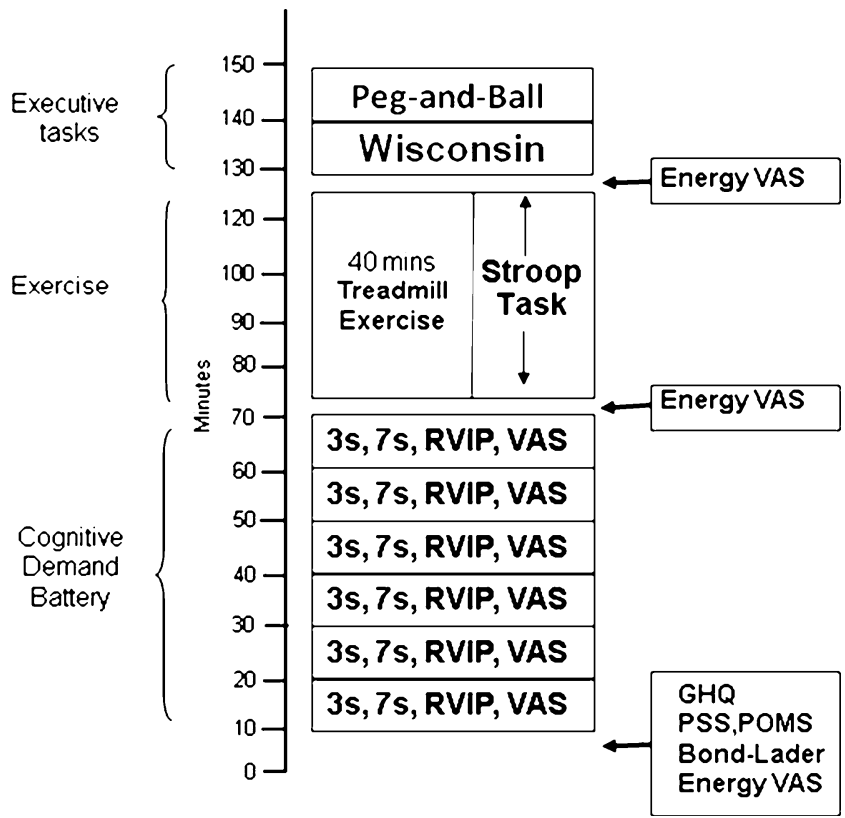

Fig. 2 Testing schedule during the final laboratory visit (day $33 \pm 2$ days) analysed with two-way (treatment $\times$ repetition) ANCOVA using the respective averaged pre-treatment assessment score as a covariate.

\section{Stroop task}

Stroop scores were collapsed into four 10-minute epochs and analysed by two-way (treatment $\times$ epoch) ANOVA.

\section{Executive function}

The peg-and-ball task and Wisconsin card sort scores and the final 'Energy VAS' were analysed with one-way (treatment) ANOVA. For those measures that included more than one post-treatment assessment a priori planned comparisons were made using $t$ tests calculated with the Mean Squares Error from the ANCOVA. In order to reduce the potential for Type I errors only those planned comparisons associated with a statistically significant difference or trend $(p<0.1)$ towards the same showing a treatment $\times$ repetition term are reported. Given this, and the exploratory nature of the study, the exponentially reducing probability of significant differences occurring for one treatment at two or more consecutive time points by chance, and an a priori statistical analysis plan for the study that precluded the report or interpretation of isolated significant differences, no correction was applied for family wise error rate across time points.

Power

A power calculation carried out a priori indicated that a total sample size of 200 would be adequate in order to have $>80 \%$ power to detect differences between treatment groups of moderate effect size (in accordance with Cohen 1988). 


\section{Results}

Demographics and baseline measures

There were no significant baseline differences between the two groups on any performance/questionnaire measures. However, those in the multi-vitamins/minerals group reported consuming significantly more portions of fruit/ vegetables on average per day than those in the placebo group $[F(1,208)=4.62, p<0.05]$. Therefore, in addition to pre-treatment score where applicable, fruit/vegetable intake was included as a further covariate in the analysis of posttreatment scores reported below. Results from ANCOVAs both with and without 'fruit and vegetable consumption' as a covariate are presented in Tables 2, 3 and 4 .

\section{Questionnaires}

Treatment with multi-vitamins/minerals led to a number of significant improvements on the questionnaire meas- ures. Participants ratings of their general mental health were improved in comparison to placebo, as evinced by reduced scores on the GHQ-12 $[F(1,205)=4.52, p<0.05]$. Similarly they reported lower subjective stress, as measured by the PSS, in comparison to placebo $[F(1,205)=$ 5.24, $p<0.05$ ].

Overall scores on the POMS also revealed a trend towards improved mood that narrowly failed to reach significance $[F(1,196)=3.77, p=0.054]$ following multivitamins/minerals compared to placebo. Reference to the POMS sub-scales showed a significant increase in selfreported 'vigour' ratings $[F(1,196)=6.03, p<0.05]$ and a non-significant trend $[F(1,196)=3.43, p=0.07]$ towards reduced 'confusion' levels following treatment in comparison to placebo.

Unadjusted mean scores (plus SDs) and $F$ scores from the ANCOVAS for the above measures are presented in Table 2. The adjusted means for those measures that showed significant effects, or trends towards the same, are presented graphically in Fig. 3.

Table 2 Pre- and post-treatment (day $33 \pm 2$ ) questionnaire mood scores

\begin{tabular}{|c|c|c|c|c|c|c|c|c|c|c|c|}
\hline \multirow[t]{2}{*}{ Instrument } & \multirow[t]{2}{*}{ Subscale } & & \multirow[t]{2}{*}{$N$} & \multicolumn{2}{|c|}{$\begin{array}{l}\text { Pre-treatment } \\
(\text { day }-2)\end{array}$} & \multicolumn{2}{|c|}{$\begin{array}{l}\text { Post-treatment } \\
\text { (day33) }\end{array}$} & \multicolumn{2}{|c|}{ ANCOVA $^{\mathrm{a}}$} & \multicolumn{2}{|c|}{$\begin{array}{l}\text { ANCOVA }^{\mathrm{b}}+\text { fruit/veg } \\
\text { covariate }\end{array}$} \\
\hline & & & & & & & & $F$ & $p$ & $F$ & $p$ \\
\hline GHQ & & $\begin{array}{l}\text { Placebo } \\
\text { Vitamin/mineral }\end{array}$ & $\begin{array}{l}107 \\
102\end{array}$ & $\begin{array}{l}9.86 \\
9.99\end{array}$ & $\begin{array}{l}3.37 \\
3.62\end{array}$ & $\begin{array}{l}9.14 \\
8.30\end{array}$ & $\begin{array}{l}3.70 \\
3.61\end{array}$ & 3.63 & 0.06 & 4.50 & $<0.05$ \\
\hline \multicolumn{2}{|l|}{ PSS } & $\begin{array}{l}\text { Placebo } \\
\text { Vitamin/mineral }\end{array}$ & $\begin{array}{l}107 \\
102\end{array}$ & $\begin{array}{l}13.0 \\
14.2\end{array}$ & $\begin{array}{l}5.25 \\
6.09\end{array}$ & $\begin{array}{l}12.9 \\
12.4\end{array}$ & $\begin{array}{l}5.54 \\
4.95\end{array}$ & 4.07 & $<0.05$ & 5.20 & $<0.05$ \\
\hline \multirow[t]{7}{*}{ POMS } & Tension & $\begin{array}{l}\text { Placebo } \\
\text { Vitamin/mineral }\end{array}$ & $\begin{array}{l}100 \\
100\end{array}$ & $\begin{array}{l}16.0 \\
17.2\end{array}$ & $\begin{array}{l}4.58 \\
5.90\end{array}$ & $\begin{array}{l}15.8 \\
16.3\end{array}$ & $\begin{array}{l}4.95 \\
5.23\end{array}$ & 0.10 & - & 0.16 & - \\
\hline & Depression & $\begin{array}{l}\text { Placebo } \\
\text { Vitamin/mineral }\end{array}$ & $\begin{array}{l}100 \\
100\end{array}$ & $\begin{array}{l}21.7 \\
22.4\end{array}$ & $\begin{array}{l}7.52 \\
8.45\end{array}$ & $\begin{array}{l}21.9 \\
21.1\end{array}$ & $\begin{array}{l}8.04 \\
7.12\end{array}$ & 2.06 & - & 2.1 & - \\
\hline & Anger & $\begin{array}{l}\text { Placebo } \\
\text { Vitamin/mineral }\end{array}$ & $\begin{array}{l}100 \\
100\end{array}$ & $\begin{array}{l}19.5 \\
20.3\end{array}$ & $\begin{array}{l}6.41 \\
7.47\end{array}$ & $\begin{array}{l}20.0 \\
19.6\end{array}$ & $\begin{array}{l}6.53 \\
6.35\end{array}$ & 1.36 & - & 1.77 & - \\
\hline & Vigour & $\begin{array}{l}\text { Placebo } \\
\text { Vitamin/mineral }\end{array}$ & $\begin{array}{l}100 \\
100\end{array}$ & $\begin{array}{l}24.7 \\
24.0\end{array}$ & $\begin{array}{l}5.63 \\
5.14\end{array}$ & $\begin{array}{l}25.2 \\
26.3\end{array}$ & $\begin{array}{l}5.60 \\
5.29\end{array}$ & 6.18 & $<0.05$ & 6.00 & $<0.05$ \\
\hline & Fatigue & $\begin{array}{l}\text { Placebo } \\
\text { Vitamin/mineral }\end{array}$ & $\begin{array}{l}100 \\
100\end{array}$ & $\begin{array}{l}14.5 \\
15.5\end{array}$ & $\begin{array}{l}5.01 \\
5.75\end{array}$ & $\begin{array}{l}14.3 \\
14.1\end{array}$ & $\begin{array}{l}6.12 \\
5.59\end{array}$ & 1.62 & - & 2.10 & - \\
\hline & Confusion & $\begin{array}{l}\text { Placebo } \\
\text { Vitamin/mineral }\end{array}$ & $\begin{array}{l}100 \\
100\end{array}$ & $\begin{array}{l}12.9 \\
13.8\end{array}$ & $\begin{array}{l}3.78 \\
4.13\end{array}$ & $\begin{array}{l}12.9 \\
12.7\end{array}$ & $\begin{array}{l}3.98 \\
3.97\end{array}$ & 3.26 & 0.07 & 3.40 & 0.07 \\
\hline & Total Score & $\begin{array}{l}\text { Placebo } \\
\text { Vitamin/mineral }\end{array}$ & $\begin{array}{l}100 \\
100\end{array}$ & $\begin{array}{l}60.2 \\
65.0\end{array}$ & $\begin{array}{l}26.6 \\
30.7\end{array}$ & $\begin{array}{l}59.7 \\
57.4\end{array}$ & $\begin{array}{l}28.0 \\
27.3\end{array}$ & 3.37 & 0.07 & 3.77 & 0.05 \\
\hline Bond-Lader & Alert & $\begin{array}{l}\text { Placebo } \\
\text { Vitamin/mineral }\end{array}$ & $\begin{array}{l}105 \\
98\end{array}$ & $\begin{array}{l}62.9 \\
61.4\end{array}$ & $\begin{array}{l}12.6 \\
12.6\end{array}$ & $\begin{array}{l}66.4 \\
67.1\end{array}$ & $\begin{array}{l}13.9 \\
14.6\end{array}$ & 1.12 & - & 1.12 & - \\
\hline & Content & $\begin{array}{l}\text { Placebo } \\
\text { Vitamin/mineral }\end{array}$ & $\begin{array}{l}105 \\
98\end{array}$ & $\begin{array}{l}66.0 \\
63.9\end{array}$ & $\begin{array}{l}13.1 \\
12.9\end{array}$ & $\begin{array}{l}68.6 \\
68.4\end{array}$ & $\begin{array}{l}14.3 \\
14.5\end{array}$ & 0.92 & - & 0.92 & - \\
\hline & Calm & $\begin{array}{l}\text { Placebo } \\
\text { Vitamin/mineral }\end{array}$ & $\begin{array}{l}105 \\
98\end{array}$ & $\begin{array}{l}62.2 \\
60.4\end{array}$ & $\begin{array}{l}12.5 \\
13.0\end{array}$ & $\begin{array}{l}65.7 \\
63.3\end{array}$ & $\begin{array}{l}14.4 \\
15.3\end{array}$ & 0.30 & - & 0.30 & - \\
\hline
\end{tabular}

Data are mean unadjusted scores plus standard deviations, with $F$ scores and probabilities from a one-way ANCOVA of day 33 data using pretreatment (day -2) scores as a covariate and with and without 'fruit/vegetable' consumption as an additional covariate

${ }^{a}$ ANCOVA including pre-treatment baseline data as a covariate

${ }^{\mathrm{b}}$ ANCOVA including additional fruit/vegetable consumption covariate 
$\mathrm{CDB}$ scores and changes in fatigue/energy

during completion

Performance of the CDB tasks was also improved in the multi-vitamins/minerals group, with a significant main effect of treatment $[F(1,199)=4.05, p<0.05]$ showing that participants made significantly more correct Serial $3 \mathrm{~s}$ subtractions in comparison to placebo across the six repetitions of the tasks. There was also a trend towards a treatment $\times$ repetition interaction on the number of correct Serial $7 \mathrm{~s}$ subtractions $[F(1,199)=1.93, p=0.09]$. Reference to the planned comparisons revealed that participants made significantly more correct responses following the first repetition of the task $[t(995)=3.53, p<0.0005]$, with a trend towards the same during the second repetition $[t(995)=$ 1.73, $p=0.08]$. There were no effects on the number of errors. There were no interpretable effects on rapid visual information processing.

In terms of the effects of task completion on ratings of mental fatigue, there was a trend towards a beneficial treatment related main effect on ratings of 'mental fatigue' across repetitions of the CDB $[F(1,198)=2.90, p=0.09]$ in comparison to the placebo group. There was also a main effect of treatment on the 'Energy VAS' ratings of 'mental tiredness' made before and after the CDB $[F(1,198)=4.90$, $p<0.05]$ with those in the multi-vitamins/minerals group reporting lower levels of 'mental tiredness' than those in the placebo group across both ratings.

Unadjusted mean scores (plus SDs) from the CDB, including $F$ scores from the ANCOVAS, are presented in Table 3 with data from the pre- and post-CDB completion of the 'energy VAS' presented in Table 4. The adjusted means for those measures that showed significant effects, or trends towards the same, are presented graphically in Fig. 4.

\section{Stroop and executive tasks}

There were no significant effects of treatment on performance of the Stroop, peg-and-ball or WCS tasks. Nor was the final 'Energy VAS', completed following all tasks, significantly modulated.

\section{Discussion}

The current study demonstrates that 33 days supplementation with a $\mathrm{B}$ complex, vitamin $\mathrm{C}$ and minerals product $\left(\right.$ Berocca $^{\circledR}$ ) benefited healthy males in terms of significantly improved ratings of general mental health (GHQ-12), reduced subjective stress (PSS) and increased ratings of 'vigour' (POMS), with a strong trend towards an overall improvement in mood as assessed by the POMS. Task performance, in terms of the number of correct Serial $3 \mathrm{~s}$ subtractions throughout the six repetitions of the $\mathrm{CDB}$ tasks, and Serial $7 \mathrm{~s}$ during the first repetition, was also improved. This was accompanied by reduced ratings of 'mental tiredness' during CDB task performance and a trend towards reduced 'mental fatigue'. The analysis omitting 'fruit and vegetable' consumption as a covariate showed a similar pattern, albeit with slightly weaker results on the GHQ-12 and POMS measures (see Tables 2, 3 and 4). Prior to treatment, there were no significant differences between the placebo and multi-vitamin/minerals groups in performance or ratings for any of the study outcomes.

The results presented here with regards the general mental health and mood questionnaires directly confirm previous findings in cohorts of healthy adults administered the same or similar supplement. Specifically, Schlebusch et al. (2000) found that 28 days supplementation led to decreased anxiety, improved well-being and decreased stress in both men and women and Carroll et al. (2000) found that the same period of administration led, amongst other effects, to lower GHQ scores and decreased ratings of stress as assessed by the PSS in a sample of males. The results are also broadly in line with those seen following supplementation with multiple vitamins for a longer time period (12 months) by Benton et al. (1995a), with the exception that significant benefits to mood were seen only in the females within their sample of 129 healthy adults. However, it may be relevant that in this previous study only vitamins were administered, but at very high doses, and the sample employed was somewhat smaller than the current study.

The benefits to task performance were largely restricted here to an increase in correct subtractions across repetitions on the Serial $3 \mathrm{~s}$ task following vitamins/minerals, with a similar effect seen only on the very first repetition of the Serial $7 \mathrm{~s}$ task. This differential treatment related enhancement of the two tasks has been seen previously (e.g., Reay et al. 2005; Scholey et al. 2009) and has been interpreted as reflecting the differing cognitive demands of the two tasks. In the case of the easier, and therefore faster, Serial 3s task, successful completion requires resources in terms of psychomotor function, attention, working memory and modest amounts of executive function. However, the Serial $7 \mathrm{~s}$ task is subjectively more difficult, has little reliance on psychomotor speed (as response rates are approximately halved), requires a similar amount of working memory but entails the recruitment of much greater attentional and executive resources. It is interesting to note that the improvements in mental arithmetic tasks that require attentional and executive resources are broadly in line with improved performance seen in adult females on two executive tasks (mental arithmetic and Stroop) within a multi-tasking battery following 9 weeks supplementation with multi-vitamins/minerals (Haskell et al. under review). 


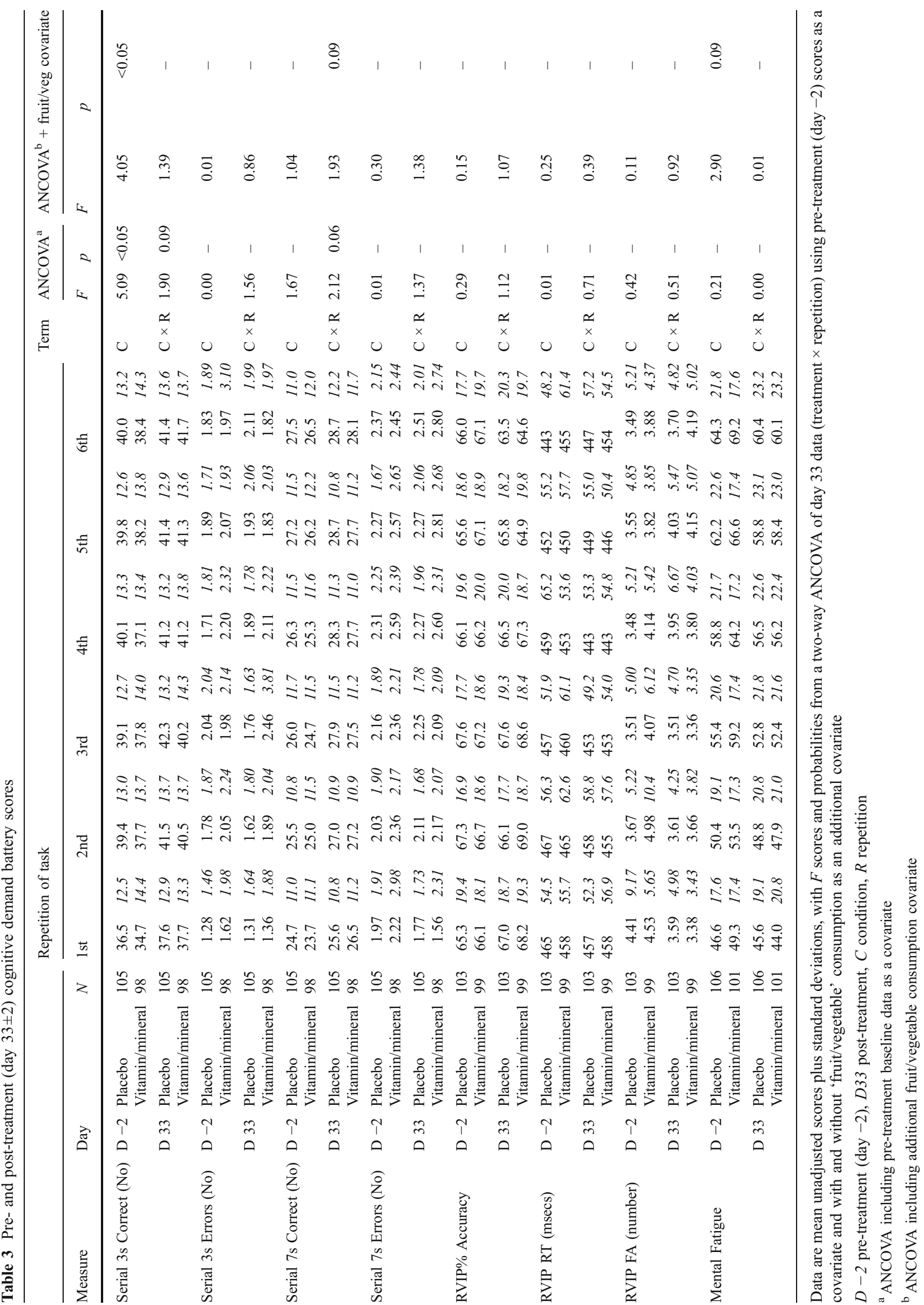


Table 4 Pre- and post- (day 33 \pm 2) energy VAS ratings pre- and post-completion of the CDB

\begin{tabular}{|c|c|c|c|c|c|c|c|c|c|c|c|c|c|c|c|}
\hline \multirow[b]{3}{*}{ Concentration } & \multirow[b]{3}{*}{ Placebo } & \multirow{3}{*}{$\begin{array}{l}N \\
105\end{array}$} & \multicolumn{4}{|c|}{ Pre-treatment (day-2) } & \multicolumn{4}{|c|}{ Post-treatment (day33) } & \multirow{3}{*}{$\begin{array}{l}\text { Term } \\
\text { Cond }\end{array}$} & \multicolumn{2}{|c|}{ ANCOVA $^{\mathrm{a}}$} & \multicolumn{2}{|c|}{$\begin{array}{l}\text { ANCOVA }^{\mathrm{b}}+\text { fruit/ } \\
\text { veg covariate }\end{array}$} \\
\hline & & & \multicolumn{2}{|c|}{$\begin{array}{l}1 \text { st } \\
\text { Assessment }\end{array}$} & \multicolumn{2}{|c|}{$\begin{array}{l}\text { 2nd } \\
\text { Assessment }\end{array}$} & \multicolumn{2}{|c|}{$\begin{array}{l}1 \text { st } \\
\text { Assessment }\end{array}$} & \multicolumn{2}{|c|}{$\begin{array}{l}\text { 2nd } \\
\text { Assessment }\end{array}$} & & \multirow[b]{2}{*}{1.29} & \multirow[b]{2}{*}{-} & \multirow[b]{2}{*}{1.40} & \multirow[b]{2}{*}{-} \\
\hline & & & 61.9 & 15.0 & 47.6 & 20.7 & 62.8 & 16.3 & 48.3 & 20.7 & & & & & \\
\hline & Vitamin/mineral & 97 & 58.7 & 15.4 & 46.7 & 21.1 & 63.6 & 14.7 & 48.7 & 19.9 & Cond $\times$ Ass & 0.00 & - & 0.00 & - \\
\hline \multirow[t]{2}{*}{ Mental Stamina } & Placebo & 105 & 60.4 & 15.2 & 42.8 & 17.6 & 61.5 & 16.2 & 44.4 & 21.0 & Cond & 1.16 & - & 1.28 & - \\
\hline & Vitamin/mineral & 97 & 57.4 & 15.9 & 44.4 & 19.6 & 61.7 & 16.8 & 47.0 & 18.5 & Cond $\times$ Ass & 0.91 & - & 0.97 & - \\
\hline \multirow[t]{2}{*}{ Physical Stamina } & Placebo & 105 & 63.0 & 16.4 & 55.6 & 18.8 & 65.2 & 17.4 & 56.8 & 18.9 & Cond & 0.00 & - & 0.01 & - \\
\hline & Vitamin/mineral & 97 & 59.4 & 16.9 & 55.8 & 19.1 & 62.9 & 17.8 & 56.9 & 19.4 & Cond $\times$ Ass & 1.49 & - & 1.29 & - \\
\hline \multirow[t]{2}{*}{ Mental Tiredness } & Placebo & 105 & 38.9 & 17.7 & 60.5 & 21.4 & 39.3 & 20.6 & 60.6 & 20.1 & Cond & 5.18 & $<0.05$ & 4.90 & $<0.05$ \\
\hline & Vitamin/mineral & 97 & 42.1 & 20.3 & 62.4 & 18.6 & 35.0 & 20.7 & 58.8 & 20.7 & Cond $\times$ Ass & 0.60 & - & 0.59 & - \\
\hline \multirow[t]{2}{*}{ Physical Tiredness } & Placebo & 105 & 36.7 & 19.7 & 44.1 & 19.8 & 34.1 & 19.0 & 41.7 & 20.9 & Cond & 0.34 & - & 0.46 & - \\
\hline & Vitamin/mineral & 97 & 38.7 & 19.8 & 44.7 & 19.8 & 37.0 & 22.2 & 42.9 & 21.9 & Cond $\times$ Ass & 0.47 & - & 0.22 & - \\
\hline
\end{tabular}

Data are mean unadjusted scores plus standard deviations, with $F$ scores and probabilities from a two-way ANCOVA of day 33 data (treatment $\times$ repetition) using pre-treatment (day -2) scores as a covariate and with and without 'fruit/vegetable' consumption as an additional covariate

Cond condition, Ass assessment

${ }^{a}$ ANCOVA including pre-treatment baseline data as a covariate

${ }^{\mathrm{b}}$ ANCOVA including additional fruit/vegetable consumption covariate

Overall, the underlying rationale for the choice of cognitive tasks employed in the study was that both the high cognitive demands of performing the difficult CDB battery tasks for $60 \mathrm{~min}$ and the general declines in executive task performance and increased mental fatigue that can be observed following extended cognitive task performance in the laboratory (Kato et al. 2009; Lorist et al. 2009) would provide a more sensitive paradigm for detecting treatment related effects. Whilst the improved performance on the Serial 3s task suggested that this may have been the case for the CDB portion of the assessment, there were no treatment related improvements seen during either the Stroop task or in performance of the two executive function tasks at the end of the assessment.

Recent Food Standards Agency surveys of the UK population show that small percentages of this and all other age/gender groups suffer biochemical deficiencies with regards each of the vitamins administered in the current study (Ruston et al. 2004), with a bias towards poorer micronutrient status in lower socio-economic status groups (Nelson et al. 2007). The sample employed here were healthy males in full-time employment. Evidence also suggests that those who participate in research tend to be better educated and more affluent than those who do not participate in research (Stopponi et al. 2009). Whilst no reference was made to any nutritional parameter as an inclusion factor and no direct analyte data was collected, the assumption was made here that the sample enjoyed typical nutritional status. However, the very fact of being able to improve mood, ratings of mental health and vigour and aspects of task performance by simple supplementation with $\mathrm{B}$ vitamins, Vitamin $\mathrm{C}$ and minerals indicates that the cohort must have been suffering from less than optimal micronutrient status at the outset. However, it is important to note that the pre-treatment scores and ratings on all of the measures employed in the study were equivalent between groups, suggesting that the results are not predicated on any pre-treatment differences in nutritional status between groups. Given that physiological levels of vitamin analytes were not established for practical reasons, the adequacy of the nutritional status of the cohort and whether the results seen here represent alleviation of deficiencies as currently defined or whether the current definitions of deficiency leave further room for functional improvement is something of a moot point. Overall, these results suggest that improving nutritional status, by supplementation if necessary, may be beneficial to males within the general population as a whole.

Interestingly, a recent study undertaken in a similar, unselected (on a nutritional basis) cohort of females who were administered a wider range of vitamins and minerals for 9 weeks demonstrated improved multi-tasking and reduced tiredness (Haskell et al. under review). In that study a sub-section of participants also volunteered to give blood samples and significant reductions in the blood levels of homocysteine were seen following supplementation in comparison to the placebo group. Whilst the relevance and causal effect of increased homocysteine levels with regards decrements in brain function have yet to be fully delineated (Elias et al. 2006), the changes seen in this potentially 


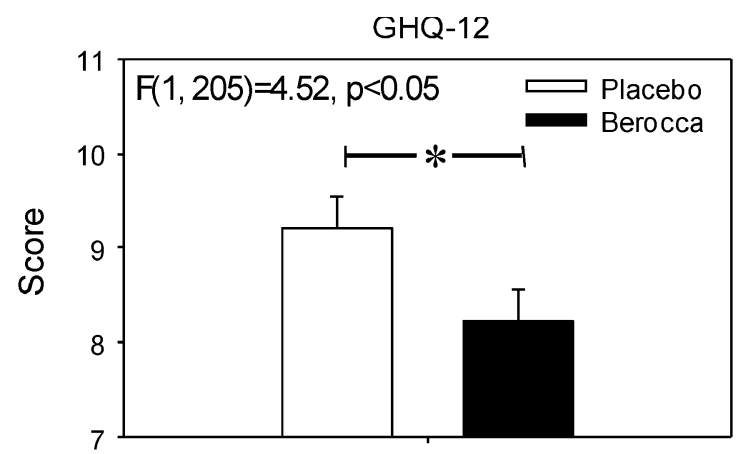

Day 33
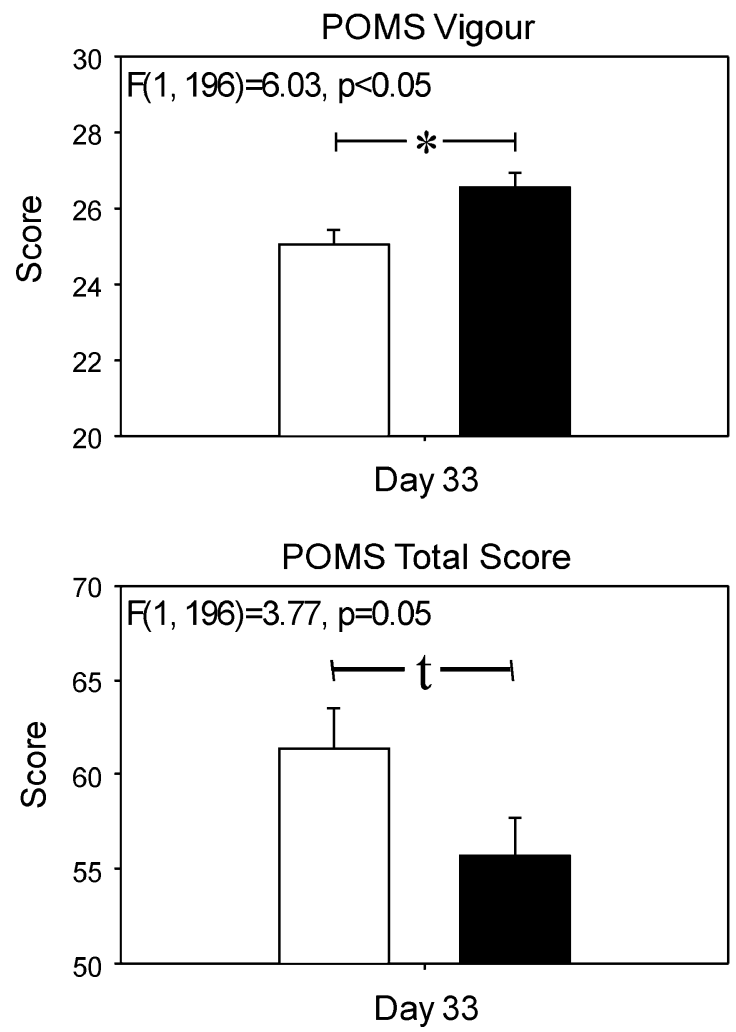

Fig. 3 Significant effects of multi-vitamins/minerals on ratings of general psychological health $(G H Q-12)$, stress (PSS) and mood $(P O M S)$. Data shown are adjusted means from one-way ANCOVAS

important physiological parameter also suggest less than optimal micronutrient status in a similar cohort of females.

Naturally, given the multiple components of the supplement administered here it is not possible to identify the specific component(s) or physiological mechanism(s) underlying the beneficial effects. Whilst, a reduction in homocysteine is plausible, the B vitamins also contribute to the integrity and synthesis of monoamine and catecholamine neurotransmitters, DNA, proteins, and phospholipids via their roles in decarboxylation and methylation processes (Mattson and Shea 2003). Vitamin C is the brain's most prevalent antioxidant and is found at its greatest concentrations in neuron rich areas. Its one-electron donor

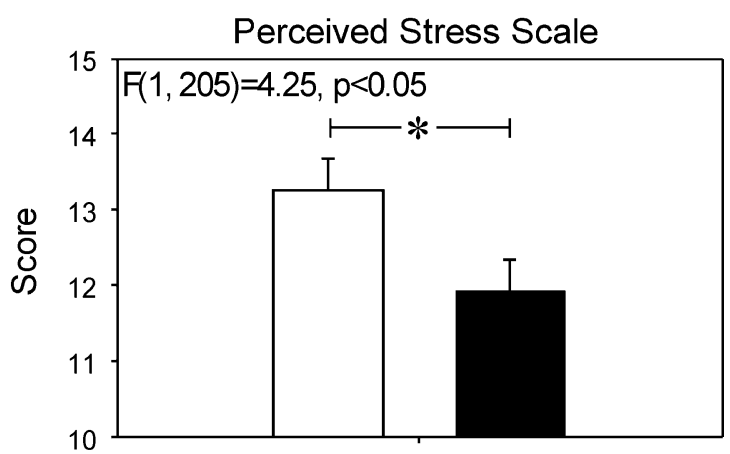

Day 33

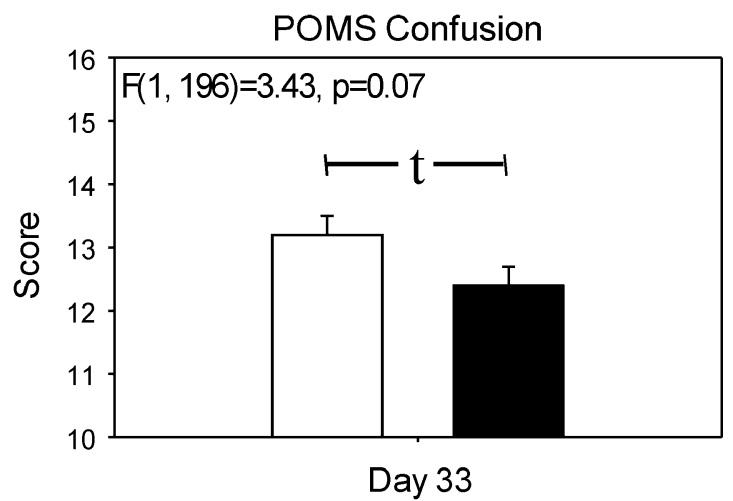

of day 33 data including pre-treatment scores and fruit/vegetable consumption as covariates. Reduced scores on the measures equate to benefits, with the exception of 'POMS vigour' $\left({ }^{*} p<0.05, t p<0.1\right)$

properties also make it an essential co-factor in a plethora of neural maturation, neuroprotection and neurotransmission processes relevant to brain function including as a modulator of cholinergic, GABAergic, dopaminergic and glutamatergic activity (Harrison and May 2009). Vitamin C was also included here at a dose $(500 \mathrm{mg})$ that approximates to the intake necessary to fully saturate plasma and circulating cells in healthy adults (Levine et al. 2001) but which is far in excess of the recommended daily allowance of $60 \mathrm{mg}$ (which is based on the levels necessary to prevent deficiency diseases).

Similarly the minerals zinc, magnesium and calcium have been highlighted as those most relevant to cognitive 

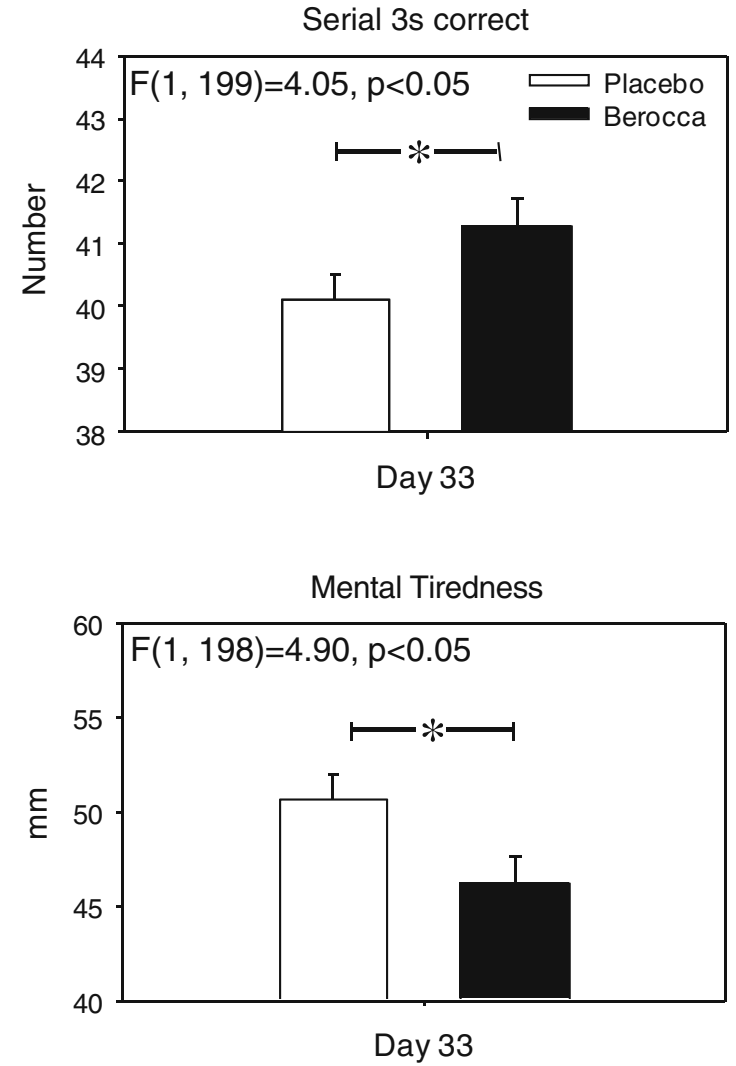

Fig. 4 Significant effects of multi-vitamins/minerals on performance of the cognitive demand battery tasks, ratings of 'mental fatigue' during the battery and ratings of 'mental tiredness' measured before and after the battery. Data shown are adjusted means from two-way

performance (Huskisson et al. 2007). Numerous nerve processes depend on calcium (Gareri et al. 1995) and it is a universal messenger of extracellular signals in a number of cells (Rasmussen 1986a, b). Magnesium plays an important role in a variety of metabolic reactions, particularly energy-requiring processes (Ryan 1991), and has been implicated in ensuring capacity for increased energy expenditure (Lukaski 2000). Zinc is essential to the structure and function of proteins and is highly concentrated in synaptic vesicles of a sub-set of glutamatergic neurons, which are particularly prevalent in the fore-brain (Frederickson et al. 2000). Neuropsychological impairment has also been highlighted as one of the major health consequences of zinc deficiency (Sandstead 2000).

The lack of data confirming pre-treatment dietary habits and circulating levels of the relevant vitamins/minerals is a limitation of the study and reduces the range of interpretations of the results. However, it is important to note that the two treatment groups did not differ in terms of cognitive task performance or their ratings on the various psychometric instruments employed in the study before treatment commenced, and given the randomised methodology and sample size, it seems reasonable to attribute the benefits
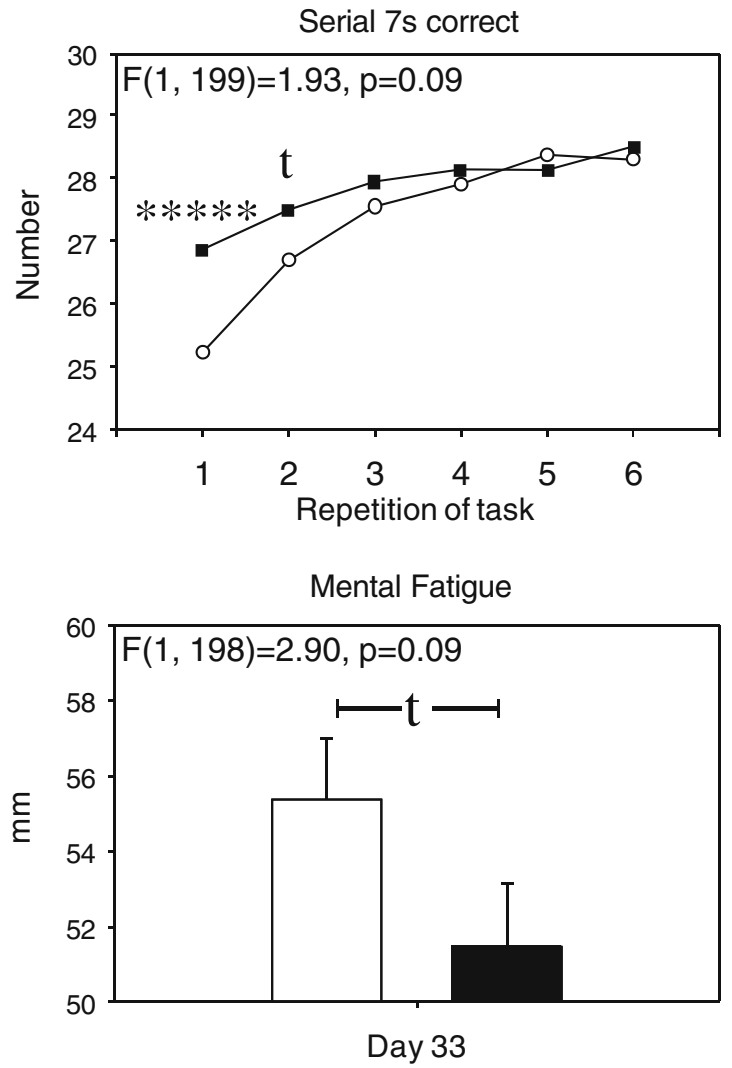

ANCOVAS (treatment $\times$ repetition) of day 33 data including averaged pre-treatment scores and fruit/vegetable consumption as covariates; $* p<0.05, t p<0.1)$

seen across a number of measures in the multi-vitamin/ mineral group to the treatment administered. Interestingly the groups did differ significantly on their self-reported consumption of fruit and vegetables (as per current definitions of 'portions'). However, this reflected greater consumption in the vitamins/minerals group. If this factor had any significant impact on the results, it might be conceived as reducing the liability of finding a positive result. The fact that including fruit/vegetable consumption as a second covariate marginally strengthens the results on two of the psychometric questionnaire measures, but does not modify the general tenor of the results, suggests that this factor may have a slight influence on the results seen here. However, it should be noted that there was no interpretable statistical relationship between this factor and scores on any measures pre-treatment across groups.

A further potential limitation of this study is that the consumption of vitamin B2 at the levels administered here can lead to discolouration of urine due to excretion of any excess. This could potentially have led to loss of blind in the current study. However, all participants (both those in the placebo group and the multi-vitamin/mineral group) were informed that ingestion of the investigational substance 
could lead to a slight yellowish discolouration of urine and that this was harmless. No information was given that might indicate that this phenomena would be linked solely to the active treatment. Participants were also instructed to record and report any health observations/changes throughout the study period, and from a total of 210 participants, only 19 reported discolouration of urine, with four of these in the placebo group (Chi-square, non-significant). This is in keeping with previous findings (Carroll et al. 2000) and suggests that the participants remained blind to treatment condition throughout the trial.

In general, few studies have assessed the cognitive performance effects of vitamins/minerals in healthy, nonelderly cohorts. Whilst the merits of investigating focussed interventions in populations at risk of disease or age-related decrements in nutritional status and physiological parameters are obvious, a good case can also be made for conducting research with multiple micronutrients delivered in the combinations that healthy end consumers are likely to purchase in their everyday lives. Taken together with previous results showing beneficial effects of vitamin/ mineral supplementation in healthy children (for reviews see Benton 2001; Eilander et al. 2010) and adults (Benton et al. 1995b; Carroll et al. 2000; Schlebusch et al. 2000), these findings further suggest that augmenting vitamin/ mineral levels in healthy, normal populations may provide beneficial effects in terms of brain function. It is unclear whether these effects represent a an offset of impairment due to marginal deficiencies or an improvement due to suboptimal levels that would not, under current guidelines, be classed as deficiency. However, given that a large section of the population are unable or unwilling to eat the adequately balanced diet that would satisfy their micronutrient requirements (Scientifc Advisory Committee on Nutrition 2008), it seems that supplementation with multi-vitamins/minerals may be a useful and possibly necessary option for this portion of the population.

Acknowledgements This study was sponsored by Bayer Consumer Care AG, Basel, Switzerland.

Open Access This article is distributed under the terms of the Creative Commons Attribution Noncommercial License which permits any noncommercial use, distribution, and reproduction in any medium, provided the original author(s) and source are credited.

\section{References}

Benton D (2001) Micro-nutrient supplementation and the intelligence of children. Neurosci Biobehav Rev 25:297-309

Benton D, Haller J, Fordy J (1995a) Vitamin supplementation for 1 year improves mood. Neuropsychobiology 32:98-105

Benton D, Fordy J, Haller J (1995b) The impact of long-term vitamin supplementation on cognitive functioning. Psychopharmacology 117:298-305
Berg EA (1948) A simple objective for measuring flexibility in thinking. J Gen Psychol 39:15-22

Bjelland I, Tell GS, Vollset SE, Refsum H, Ueland PM (2003) Folate, vitamin B-12, homocysteine, and the MTHFR $677 \mathrm{C} \rightarrow \mathrm{T}$ polymorphism in anxiety and depression: the Hordaland Homocysteine study. Arch Gen Psychiatry 60:618-626

Black MM (1996) Zinc deficiency and child development. Baltimore, Maryland, pp 464S-469S

Bond A, Lader M (1974) Use of analog scales in rating subjective feelings. Br J Med Psychol 47:211-218

Cardoso CC, Lobato KR, Binfaré RW, Ferreira PK, Rosa AO, Santos ARS, Rodrigues ALS (2009) Evidence for the involvement of the monoaminergic system in the antidepressant-like effect of magnesium. Prog Neuro Psychopharmacol Biol Psychiatry 33:235-242

Carroll D, Ring C, Suter M, Willemsen G (2000) The effects of an oral multivitamin combination with calcium, magnesium, and zinc on psychological well-being in healthy young male volunteers: a double-blind placebo-controlled trial. Psychopharmacology 150:220-225

Cohen J (1988) Statistical Power Analysis for the Behavioral Sciences (second ed.). Lawrence Erlbaum Associates

Cohen S, Kamarck T, Mermelstein R (1983) A global measure of perceived stress. J Health Soc Behav 24:385-396

Del Parigi A, Panza F, Capurso C, Solfrizzi V (2006) Nutritional factors, cognitive decline, and dementia. Brain Res Bull 69:1-19

Durga J, van Boxtel MPJ, Schouten EG, Bots ML, Kok FJ, Verhoef $P$ (2006) Folate and the methylenetetrahydrofolate reductase $677 \mathrm{C} \rightarrow \mathrm{T}$ mutation correlate with cognitive performance. Neurobiol Aging 27:334-343

Durga J, van Boxtel MPJ, Schouten EG, Kok FJ, Jolles J, Katan MB, Verhoef P (2007) Effect of 3-year folic acid supplementation on cognitive function in older adults in the FACIT trial: a randomised, double blind, controlled trial. Lancet 369:208-216

Duthie SJ, Whalley LJ, Collins AR, Leaper S, Berger K, Deary IJ (2002) Homocysteine, B vitamin status, and cognitive function in the elderly. Am J Clin Nutr 75:908-913

Eilander A, Gera T, Sachdev HS, Transler C, van der Knaap HC, Kok FJ, Osendarp SJ (2010) Multiple micronutrient supplementation for improving cognitive performance in children: systematic review of randomized controlled trials. Am J Clin Nutr 91:115-130

Elias MF, Robbins MA, Budge MM, Elias PK, Brennan SL, Johnston C, Nagy Z, Bates CJ (2006) Homocysteine, folate, and vitamins B-6 and B-12 blood levels in relation to cognitive performance: the Maine-Syracuse study. Psychosom Med 68:547-554

Elias MF, Robbins MA, Budge MM, Elias PK, Dore GA, Brennan SL, Johnston C, Nagy Z (2008) Homocysteine and cognitive performance: modification by the ApoE genotype. Neurosci Lett 430:64-69

Engelhart MJ, Geerlings MI, Ruitenberg A, van Swieten JC, Holman A, Witteman JCM, Breteler MMB (2002) Dietary intake of antioxidants and risk of Alzheimer disease. Jama J Am Med Assoc 287:3223-3229

Feng L, Ng TP, Chuah L, Niti M, Kua EH (2006) Homocysteine, folate, and vitamin B-12 and cognitive performance in older Chinese adults: findings from the Singapore Longitudinal Ageing Study. Am J Clin Nutr 84:1506-1512

Frederickson CJ, Suh SW, Silvia D, Frederickson CJ, Thompson RB (2000) Importance of zinc in the central nervous system: the zinc-containing neuron. J Nutr 130:1471S-1483S

Gareri P, Mattace R, Nava F, De Sarro G (1995) Role of calcium in brain aging. Gen Pharmacol Vasc Syst 26:1651-1657

Goldberg DP, Gater R, Sartorius N, Ustun TB, Piccinelli M, Gureje O, Rutter C (1997) The validity of two versions of the GHQ in the WHO study of mental illness in general health care. Psychol Med 27:191-197 
Harrison FE, May JM (2009) Vitamin C function in the brain: vital role of the ascorbate transporter SVCT2. Free Radic Biol Med 46:719-730

Haskell CF, Scholey AB, Jackson PA, Elliott JM, Defeyter MA, Greer J, Robertson BC, Buchanan T, Tiplady B, Kennedy DO (2008) Cognitive and mood effects in healthy children during 12 weeks' supplementation with multi-vitamin/minerals. Br J Nutr 100:10861096

Huskisson E, Maggini S, Ruf M (2007) The influence of micronutrients on cognitive function and performance. J Int Med Res 35:1-19

Kado DM, Karlamangla AS, Huang MH, Troen A, Rowe JW, Selhub J, Seeman TE (2005) Homocysteine versus the vitamins folate, B-6, and B-12 as predictors of cognitive function and decline in older high-functioning adults: MacArthur studies of successful aging. Am J Med 118:161-167

Kato Y, Endo H, Kizuka T (2009) Mental fatigue and impaired response processes: event-related brain potentials in a $\mathrm{Go} / \mathrm{NoGo}$ task. Int J Psychophysiol 72:204-211

Kennedy DO, Scholey AB (2004) A glucose-caffeine 'energy drink' ameliorates subjective and performance deficits during prolonged cognitive demand. Appetite 42:331-333

Kennedy DO, Haskell CF, Robertson B, Reay J, Brewster-Maund C, Luedemann J, Maggini S, Ruf M, Zangara A, Scholey AB (2008) Improved cognitive performance and mental fatigue following a multi-vitamin and mineral supplement with added guarana (Paullinia cupana). Appetite 50:506-513

Kim JM, Stewart R, Kim SW, Yang SJ, Shin IS, Yoon JS (2008) Predictive value of folate, vitamin B-12 and homocysteine levels in late-life depression. Br J Psychiatry 192:268-274

Levine M, Wang Y, Padayatty SJ, Morrow J (2001) A new recommended dietary allowance of vitamin $\mathrm{C}$ for healthy young women. Proc Natl Acad Sci USA 98:9842-9846

Lorist MM, Bezdan E, ten Caat M, Span MM, Roerdink JBTM, Maurits NM (2009) The influence of mental fatigue and motivation on neural network dynamics; an EEG coherence study. Brain Res 1270:95-106

Lukaski HC (2000) Magnesium, zinc, and chromium nutriture and physical activity. Am J Clin Nutr 72(suppl):585S-593S

Malouf R, Grimley Evans J (2003) The effect of vitamin B6 on cognition. Cochrane Database Systematic Reviews Issue 4. Art No.: CD004393. doi:10.1002/14651858.CD004393

Malouf R, Grimley Evans J (2008) Folic acid with or without vitamin B12 for the prevention and treatment of healthy elderly and demented people. Cochrane Database of Systematic Reviews Issue 4. Art. No.: CD004514. doi:10.1002/14651858.CD004514.pub2

Mattson MP, Shea TB (2003) Folate and homocysteine metabolism in neural plasticity and neurodegenerative disorders. Trends Neurosci 26:137-146

McNair PM, Lorr M, Droppleman L (1992) POMS Manual: Profile of Mood States. Educational and Industrial Testing Service, Educational and Industrial Testing Service

Morris MC (2009) The role of nutrition in Alzheimer's disease: epidemiological evidence. Eur J Neurol 16:1-7
Muthayya S, Eilander A, Transler C, Thomas T, van der Knaap HC, Srinivasan K, van Klinken BJ, Osendarp SJ, Kurpad AV (2009) Effect of fortification with multiple micronutrients and n-3 fatty acids on growth and cognitive performance in Indian schoolchildren: the CHAMPION (Children's Health and Mental Performance Influenced by Optimal Nutrition) Study. Am J Clin Nutr 89:1766-75

Nelson M, Erens B, Bates B, Church S, Boshier T (2007) Low Income Diet and Nutrition Survey. TSO, London

Scientific Advisory Committee on Nutrition (2008) The Nutritional Wellbeing of the British Population. TSO

Rasmussen H (1986a) The calcium messenger system (1). N Engl J Med 314:1094-1101

Rasmussen H (1986b) The calcium messenger system (2). N Engl J Med 314:1164-1170

Reay JL, Kennedy DO, Scholey AB (2005) Single doses of Panax ginseng (G115) reduce blood glucose levels and improve cognitive performance during sustained mental activity. J Psychopharmacol 19:357-365

Ruston D, Hoare J, Henderson L, Gregory J, Bates C, Prentice A, Birch M, Swan G, Farron M (2004) National Diet and Nutrition Survey: adults aged 19-64 years. Volume 4: Nutritional Status (anthropometry and blood analytes), blood pressure and physical activity. TSO

Ryan MF (1991) The role of magnesium in clinical biochemistry: an overview. Ann Clin Biochem 28:19-26

Sanchez-Villegas A, Doreste J, Schlatter J, Pla J, Bes-Rastrollo M, Martinez-Gonzalez MA (2009) Association between folate, vitamin B-6 and vitamin B-12 intake and depression in the SUN cohort study. J Hum Nutr Diet 22:122-133

Sandstead HH (2000) Causes of iron and zinc deficiencies and their effect on brain. J Nutr 130:347S-349S

Schlebusch L, Bosch BA, Polglase G, Kleinschmidt I, Pillay BJ, Cassimjee MH (2000) A double-blind, placebo-controlled, double-centre study of the effects of an oral multivitaminmineral combination on stress. S Afr Med J 90:1216-1223

Scholey AB, French SJ, Morris PJ, Kennedy DO, Milne AL, Haskell CF (2010) Consumption of cocoa flavanols results in acute improvements in mood and cognitive performance during sustained mental effort. Journal of Psychopharmacology first published on November 26, 2009 as doi:10.1177/0269881109106923

Stopponi MA, Alexander GL, McClure JB, Carroll NM, Divine GW, Calvi JH, Rolnick SJ, Strecher VJ, Johnson CC, Ritzwoller DP (2009) Recruitment to a randomized web-based nutritional intervention trial: characteristics of participants compared to non-participants. J Med Internet Res 11:e38

Tiemeier H, van Tuiji HR, Hofman A, Meijer J, Kiliaan AJ, Breteler MMB (2002) Vitamin B-12, folate, and homocysteine in depression: the Rotterdam study. Am J Psychiatry 159:2099-2101

van der Linden D, Frese M, Meijman TF (2003) Mental fatigue and the control of cognitive processes: effects on perseveration and planning. Acta Psychol 113:45-65

Vidal JS, Dufouil C, Ducros V, Tzourio C (2008) Homocysteine, folate and cognition in a large community-based sample of elderly people - the 3C Dijon study. Neuroepidemiology 30:207-214 